\title{
INTERSTELLAR DUST AS THE SOURCE OF ORGANIC MOLECULES IN COMET HALLEY
}

\section{J. M. Greenberg}

Laboratory of Astrophysics, University of Leiden, P.O. Box 9504, Niels

Bohrweg 2, 2333 CA Leiden, The Netherlands

\section{ABSTRACT}

Interstellar dust is described as consisting predominantly (by mass) of tenth micron (mean size) silicate core-organic refractory mantle particles which have evolved over galactic time scales of the order of 5 billion years. These particles were incorporated into comets and asterolds in the presolar nebula 4.5 billion years ago. The fragmentation of those primitive bodies gives rise to solar system debris which shows up as comet dust, zodiacal light, IDP's and meteorites. The chemical and morphological structure of comet dust is derived here as fluffy aggregates of interstellar dust. The chemlcal and morphological structure of the chondritic porous IDP's are then derived from comet dust which has evolved in the solar system. Zodiacal 11ght particles are interpreted as varlous stages between comet dust and IDP's. Meteorites appear to be a side branch in the evolution from intersteliar to solar system particles.

\section{INTRODUCTION}

How far removed in chemistry and morphology are the small particles in the solar system from their progenitors - the interstellar dust? Can we expect to find really close similarities? What we see at the present time in the form of comet dust, zodiacal 1lght, meteors, IDP's, and meteorites must have originated in larger bodies which formed 4.5 billion years ago. Not only could these parent bodles have undergone significant metamorphosis in the aggregation stage but we might expect to find further changes to have occurred both within the parent bodies as well as from chemical and physical changes in the solar system following fragmentation. It is therefore at first glance almost inconcelvable that close resemblances with solar system particles are traceable to the original interstellar dust. In some cases as with comet dust and IDP's - it appears remarkably close.

SIZE, SHAPE AND COMPOSITION OE INTERSTELLAR DUST

Recent studies of the observations of so-called diffuse cloud dust (dust not in molecular clouds) in the ultraviolet have revealed the fact that there are three populations of dust 11 . There are elongated "large" gralns of - $0.12 \mu \mathrm{m}$ in mean radius which provide the major blockling of starlight in the visual. There are also very small carbonaceous particles of $\leq 0.01 \mu \mathrm{m}$ in radius which produce a strong absorption feature at about $220 \mathrm{~nm} / 2 /$. In addition there is an independent population of - 0.01 um silicate type particles. Large carbon bearing molecules (or very small particles) like PAH's/3/ consume a small ( $\leq 5 \%$ ) of the carbon.

The evolutionary picture of dust which is emerging is a cyclic one in which the particles, before being destroyed or going into solar system bodies, find thenselves alternately over many cycles in diffuse clouds and in molecular clouds $/ 4,5,6$. A small silicate core captured 
Wlthin a molecular cloud accretes varlous lces and gradually bullds up an Inner mantle of organic refractory material which has been produced by photoprocessing of the volatile ices. Since the silicates which are formed in cool evolved stars are not crystalline, the elongation required for polarization in the $10 \mu \mathrm{m}$ (S1-O stretch) band must be due to connected more-or-less spherical sllicate beads. Representation of the core-mantle partlcles by concentric cylinders has been a mathematical convenience. The organic refractory mantles are subjected to the highest photoprocessing rates in the diffuse cloud phase - higher by sactors of 10,000 or so than in the molecular cloud. Because of the cyclic evolution the organic refractory mantle on a grain is not $a$ homogeneous substance but rather layered like the rings of a tree trunk in which the innermost layers have been the most irradiated and the outermost layer in the most recent molecular cloud phase is first generation organic refractory which is surrounded finally by lightly photoprocessed ices of which $\mathrm{H}_{2} \mathrm{O}$ is the dominant component. Since further photoprocessing of organlcs leads to a greater and greater depletion of $\mathrm{O}, \mathrm{N}$, and $\mathrm{H}$, the innermost layers are the most "carbonlzed" and the most nonvolatile.

A schematic representation of grains in the various regions of space is shown in Fig. 1. Theoretical calculations of core-mantie particles have been shown to match the observed

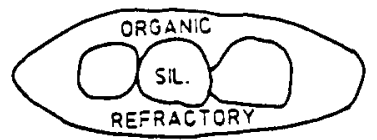

DIFFUSE CLOUD GRAIN.

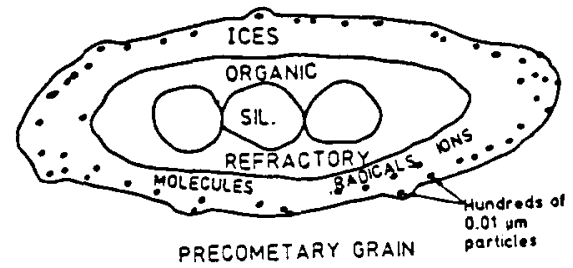

Fig. 1. Interstellar gralns as core-mantle structures. The solid bar is $1 \mu \mathrm{m}$.

extinction and polarization as $w 911$ as the albedo of interstellar dust /8/. In the final stage of cloud condensation we may expect that all remaining (condensable) molecules will have accreted onto the dust. In addition, the very small ( $0.01 \mathrm{\mu m}$ ) particles will be collected and trapped within the outer volatile lcy mantle.

Our focus here will be on establishing a relatlonship between the chemical and morphological structure of presolar interstellar dust and comet dust, interplanetary dust, and meteorites.

\section{DUST AGGREGATION AND MORPHOLOGY}

In our solar system all of the planets and satellites have incorporated into their bodies at least the most refractory components of the intersteliar dust which existed in the pre-solar nebula. Comets, appear likely to have preserved their original composition best including their volatiles not only because the volatile molecule $S_{2}$ may be traced back to the photochemlcal evolution of the interstellar dust $19 /$ but also because of the observed $\mathrm{CH}_{4} / \mathrm{H}_{2} \mathrm{O}$ rat10 $/ 10 /$.

As a first approximation, therefore, we consider a comet nucleus as if its chemical composition and morphological structure are directly related to interstellar dust. Table 1 shows the relative fractions of the various chemlcal constltuents which have been obtained by 
an extrapolation from the molecular cloud dust phase $/ 11,12 /$.

TABLE 1 Suggested mass distribution of the frincipal chemical constituents of a cometesimal based on the dust model. Parentheses refer to very small particle components $(a \leq 0.01 \mathrm{\mu m}) . / 7 \%$.

\section{Component}

\section{Stilcates}

Carbon (carbonaceous)

Nonvolatile Complex

Organic Refractory

$\mathrm{H}_{2} \mathrm{O}$

co

Other Molecules + Radicais

$\left(\mathrm{H}_{2} \mathrm{CO}, \mathrm{NH}_{3}, \mathrm{OCN}^{-}, \mathrm{CO}_{2}\right.$

$\mathrm{HCO}, \mathrm{S}_{2}, \mathrm{CH}_{3} \mathrm{OH} \ldots$ )
Mass Fraction

$0.14+(0.06)$

$(0.06)$

0.19

0.37

0.05

0.13

In forming the nucleus we assume that first clumps of grains form, and then clumps of clumps, and so on, until finally we reach the size of the comet nucleus. If we should start with the interstellar dust tightly packed and then remove all the volatiles (along with the trapped super smali farticles) the resulting mean density of the remaining core-organic refractory grains skeleton is about $0.5 \mathrm{~g} \mathrm{~cm}^{-3} / 13 \%$. It is however observed that meteors (which are what is left after the original cometary volatiles have evaporated) have a characteristic density much lower than this, often being even less than $0.1 \mathrm{~g} \mathrm{~cm}^{-3}$. This leads to a packing factor of 0.2 ; 1.e., a comet is about $80 \%$ empty space! A model of such an open aggregate of 100 typical precometary grains is shown in Fig. $2 a$.
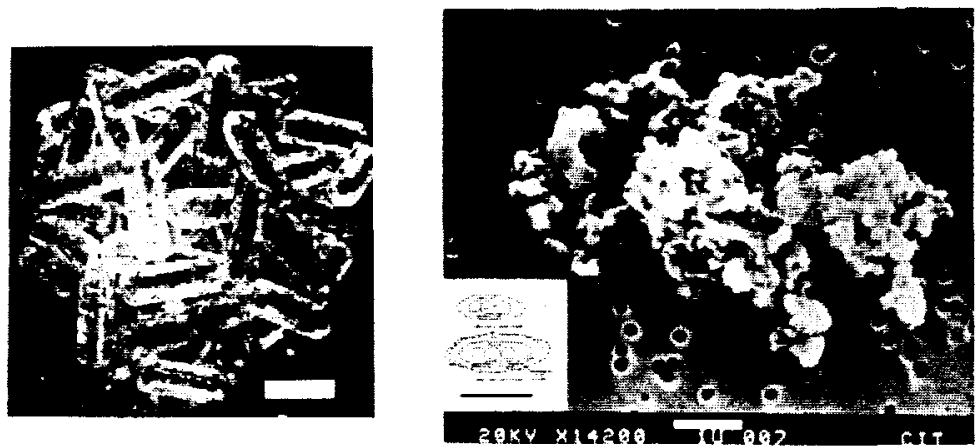

Fig. 2a: A piece of a fluffy comet: Model of an aggregate of 100 average interstellar dust particles each of which consists of a silicate core, an organic refractory inner mantie and an outer mantio of predominantly water ice in which are embedded the numerous very small $(<0.01 \mu \mathrm{m})$ particies responsible for the intersteliar $216 \mathrm{~nm}$ absorption and the far ultraviolet extinction (See Fig. 1). Each particle as represented corresponds to an intersteliar grain $1 / 2 \mu \mathrm{m}$ thick and abolt

$1 \frac{1}{2} \mu \mathrm{m}$ long. The mean mantle thickness corresponds in reality to a size distribution of thicknesses starting from zero. The packing factor of the particles is about 0.2 ( $80 \%$ empty space) and leads to a mean mass density of $0.28 \mathrm{gm} \mathrm{cm}^{-3}$ and an aggregate diameter of $5 \mu \mathrm{m}$.
Fis. 2b: A highiy porous chondritic IDP $/ 35 \%$. Note that the bird's nest particle (Fig. 2a), the IDP (Fig. 2b) and the average interstellar coremantle particle (Fig. 2b insert) are equally sealed to $1 \mu \mathrm{m}$. 
Of course. $\mathrm{H}_{2} \mathrm{O}$, was the most abundant molecule deduced in the coma of comet Halley. The next mos: abundani species is CO. For exampie Krankowsky et ai. $114 /$ found a ratio $Q_{\mathrm{CO}} / \mathrm{Q}_{\mathrm{H}_{2} \mathrm{O}}=0.03$ and infrared data gave $Q_{\mathrm{CO}_{2}} / Q_{\mathrm{H}_{2} \mathrm{O}}=10^{-\frac{2}{2}}$ while IUE observations $/ 15 /$ gave $Q_{\mathrm{CO}} / Q_{\mathrm{H}}=0.1-0.2$. These values are more or less within the ranges suggested by the volatile composition of intersteliar dust $/ 15,17,18 \%$. There are two posslble sources of $c 0$. One of these is, of course, as part of the ine which evaporates from the grains. Another is the photodissociation of the more volatile molecules of the organic refractory component. The existence of carboxylic acld groups in laboratory first generation orzanic residues and, by inference, in the outer parts of the organio dust mantles, makes such a source highiy plausible. The existence of an extended co source in Halley $/ 19 /$ associated with the dust provides support for the fact that a large fraction of $c 0$ comes off as the dust fragments and releases small grains from which the not-so-refractory organics evaporate and are photodissoclated (see section d for other gas components from dust). There is no definite evidence for the presence of $\mathrm{NH}_{3}$ in the ion mass spectra /20/ and there may even be a lack of nitrogen in the coma gas. This is yet to be definitely confirmed but one possible reason could be that nitrogen is strongly bound in the organic refractories and is rather part of the dust than directly in volatile forms like $\mathrm{NH}$, and $\mathrm{N}_{2}$. Although $\mathrm{NH}_{3}$ had earlier been suggested to be a substantial component of intersteliar dust the observational evidence $/ 21 \%$, as well as theoretical arguments lead to generally rather small amounts of $\mathrm{NH}_{3}$ in graln mantles and possible more $\mathrm{N}_{2}$ 1221.

It was noted by Balsiger et 31 . $/ 20 /$ that the $\mathrm{C} / 0$ ratio is about half of the cosmis abundance ratio. This had earlier been called the missing carbon mystery by Delsemme /23/ and had been attributed to the "hiding" of a large fraction of the carbon in the organic refractory component $112 \%$. The dust mass spectra where the carbon to oxygen ratio is much higher than cosmic abundance confirm this prediction $124 /$.

The dust impact mass analyzers on Vega $1 / 2$ (PUMA) and on Giotto (PIA) showed a predominance of the light elements $\mathrm{H}, \mathrm{C}, \mathrm{O}, \mathrm{N}$ (organics) relative to the heavier elements $\mathrm{Si}, \mathrm{Mg}$, Fe (rockies) in the dust $125,26 /$.

Kissel and Krueger /24/ have derived a molecular analysig of the comet dust and in particular its organic component. Masses between $2 \times 10^{-15}$ and $10^{-11} \mathrm{~g}$ were measured with the masses of most of the particles estimated to be in the range $10^{-72}-10^{-13} \mathrm{~g}$ with "systematic error within an order of magnitude". Their typical total relative atomic abundances in their moiecules (of the organic refractory) show a significant lack of oxygen just as is predicted by the interstellar dust model. A four-fold enhancement of carbon was predicted relative to oxygen $/ 11,12 /$. The ratio of organics to silicate mass deduced by $K+K$ is $m_{O R} / m_{S i l}=1: 2$ which, not surprisingly, is less than that in the interstellar dust because of the expected evaporation of the less refractory organics at solar system temperatures.

Table 2 shows the distribution of atomic constituents in the various precometary interstellar dust components based on the values in Table 1. Normalizing to Si = 100 comparison may be made with the comet dust data deduced by Kissel and krueger. This comparison is shown in Table 3. The only major discrepancy which can not be readily explained is the underabundance of $N$. For the rest it is seen how similar the atomic composition of organic refractory mantles of interstellar grains are to the comet dust organics. 
TABLE 2. Atomic constieunts of various cometary components as fraction of the cosmic abundance, based on the dust model. The hydrogen are estlmated as follows: 1 for each carbon in the organic refractory, 2 for each oxygen in $\mathrm{H}_{2} \mathrm{O}$, 1 for each carbon in "Other". 1 for each nitrogen in "Other" and 1 for each oxygen in "Other". Superscrlpt a indicates that the figure is based on graphite (which we know is not valid); $b$ indicates that the rlgures are particularly uncertain. This is because nitrogen is relatively more abundant in the organic refractory than oxygen, so the fractional (by cosmic abundance) nitrogen value could be signiflcantly higher and that of oxygen significantly lower. These changes affect "Other" accordingly.

$\begin{array}{cc}\text { Element } & \text { Sili } \\ \mathrm{H} & - \\ \mathrm{C} & - \\ \mathrm{N} & - \\ \mathrm{O} & 0.0 \\ \mathrm{Mg} & 1.0 \\ \mathrm{SI} & 1.0 \\ \mathrm{Fe} & 1.0\end{array}$

Organic
refractory
$\begin{gathered}1.7 \times 10^{-4} \\ 0.45 \\ 0.25^{b} \\ 0.13^{b} \\ - \\ - \\ -\end{gathered}$

Small carbonaceous

-
s0.
-
-
-
-
-

$\mathrm{H}_{2} \mathrm{O}$<smiles></smiles>

co

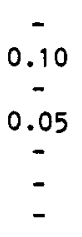

other

$$
\begin{gathered}
4.4 \times 10^{-4} \\
0.17 \\
0.75 \\
0.80 \\
- \\
-
\end{gathered}
$$

TABLE 3. Abundances in comet dust relative to Si (= 100) (KIssel and Krueger Nature 326, 755 (1987) compared with presolar intersteliar dust (ISD).

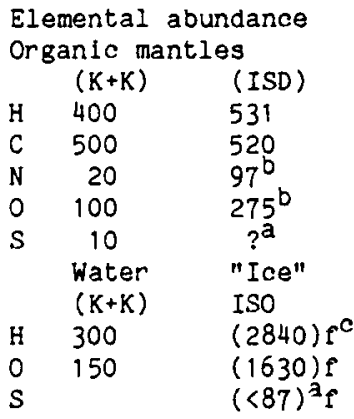

\begin{tabular}{lll} 
& \multicolumn{2}{l}{ Elemental abundance } \\
& Choudritic & Sillcate cores \\
& $(\mathrm{K}+\mathrm{K})$ & $(\mathrm{SSD})$ \\
$\mathrm{C}$ & 100 & \\
$\mathrm{O}$ & 300 & 200 \\
$\mathrm{Na}$ & 2 & \\
$\mathrm{Mg}$ & 70 & 94 \\
$\mathrm{AI}$ & 5 & \\
$\mathrm{Si}$ & 100 & 100 \\
$\mathrm{~S}$ & 40 & \\
$\mathrm{Ca}$ & 4 & 81 \\
$\mathrm{Fe}$ & 70 &
\end{tabular}

a The cosmic abundance value of $S$ used is 87 . The interstellar dust model presumes a large fraction of this to be in the volatiles (ices).

b "First" generation organic refractory. Subsequent UV radiation reduces 0 but $N$ should not be so reduced, 1.e. N/O should be higher than Cosmic Abundance in organle refractory which has been further photoprocessed in diffuse clouds.

c $f$ is the fraction of all volatiles remaining at the time of impact. A value $f=0.1$ does not seem unreasonable.

\section{COMET DUST}

The $3.4 \mu \mathrm{m}$ and $10 \mu \mathrm{m}$ excess emission in comet dust provide evidence not only for the basic chemleal ingredients - as given in the mass spectra - but also for the morphological structure $127 \%$. It turns out that pure silicates no matter how small do not achieve high enough temperatures to produce the observed 10 um emission. At, for example 1.11 AU the required temperatures needed to keep the total mass of the emitting particies at all 
reasonable is $T>430 \mathrm{~K}$. Absorbing organic refractory mantles - such as those on interstellar sllicate cores - are absolutely required to raise the compound grain temperatures high enough to make the $10 \mu \mathrm{m}$ peak observable. Furthermore, the $T>430 \mathrm{~K}$ temperature constraint leads to a most probable silicate core radius $-0.05 \mu \mathrm{m}$ and a mantle thickness $20.02 \mu \mathrm{m}$. i.e. an organic to silicate mass ratio $\mathrm{m}_{\mathrm{OR}} / \mathrm{m}_{\mathrm{s}}=0.9$ which, within the uncertainties, is like that deduced from comet dust mass spectra. If only such small particles (m $\leq 10^{-13} \mathrm{~g}$ ) could produce the $10 \mu \mathrm{m}$ (and $3.4 \mathrm{\mu m}$ ) emissions the ir fluxes would have been more than 10,000 times higher than observed. It is, only by considering them to be in fluffy aggregates that the integrated fluxes come into reasonable resemblance to the particle lmpact detector data /28/ - although still by a factor of about 25 too high for masses $\leq 10^{-9} \mathrm{~g}$.

\section{ZODIACAL LIGHT DUST}

Interplanetary dust has classically been observed via its scattering of sunilght - the zodlacal light. The addltion of infrared observations has revealed some significant physical distinctions between particles as a function of distance from the sun. Those which are within 1 AU scatter visible light much more effectively than those which are beyond 1 AU. At the same time, those which are farther out are more effective emitters of infrared radiation. This implies a difference in kind as well as number with increasing solar distance $/ 29 /$. The most obvious explanation of this phenomena is that the radial decrease of the albedo of the zodiacal light particles is produced by a decrease in material density, just as the albedo of cometary dust is decreased because of its fluffiness. The interplanetary particle probe results of Ploneer $10 / 11$ were also interpreted in terms of a radial decrease of particle denslty $130 /$.

It has been suggested that the zodlacal light is predominantly produced by particles which started out as comet dust $131 \%$. The alternative point of view is that interplanetary particles result from asteroldal collisions $/ 32 \%$. Probably something in between may be true although, if some asterolds are just inert comets, the distinction may be academic. That asterolds play only a minor role as a dust source /33/ appeared to be confirmed by the Ploneer $10 / 11$ data which did not show any dust increase in the asteroidal belt $/ 34 /$. With the assumption that most interplanetary particles start out as fluffy low albedo comet dust partlcles (1lke that in Fig. 2a), Mukal and Fechtig/35/ proposed a mechanism by which solar heating would lead to a gradual compaction of the initially fluffy dust by evaporation of the volatiles in what they called "Greenberg particles" leading to more compact and higher visual scattering partlcles like the "Brownlee particles" (Fig. 2b).

\section{COLLECTED INTERPLANETARY DUST PARTICLES (IDP'S)}

Although the mean density of the chondritic porous IDP's collected in the stratosphere is low it is much higher than the initial cometary dust. But, as has been pointed out by Brownles himself $/ 36 /$. there is no evidence of a bird's nest structure in the IDP's (Fig. 20). What we see in Fig. 2b is an aggregate of more or less spherical particles of about $0.1 \mu$ diameter whose infrared signature is that of sllicates. When the interstellar dust is scaled like the IDP we see how its sllicate core segments - which are hidden in the bird's nest model (Fig. 2a) - are like the slilicates in the IDP. But where are the organic refractory manties in the IDP's? In the original (interstellar dust) comet nucleus material the ratio of $0 . R$. mass to silicate mass is given as about 1.5:1 (Table 1). However, already in the comet dust, the loss of the more volatile O.R. molecules has led to a reduction of this ratio by about a factor of 3 to about $1: 2(\mathrm{~K}+\mathrm{K})$. Whlle the organic mantles are not "seen" in the IDP electron micrographs they become immediately apparent with Raman spectroscopy $/ 37 /$. It appears that every silicate particle is covered by some organlc mantie. The fact that the mean silicate particle size is like that of the interstellar core pieces and each silicate or clump of slicates has an O.R. coating is certainly suggestive of the interstellar origin while the bird's nest morphological structure is lost because of the removal, during the passage from the comet to the earth, of a further part of the original comet dust $O . R$.

Additional indications for the cometary to interplanetary dust evolution may be seen in the 
lower density of meteors whose aphelion distances are beyond 5.4 AU as compared with those which spend more time closer to the sun $138 /$.

\section{METEORITES}

How do meteorites and their parent asteroldal bodies fit into the cosmlc dust connection? Since the formation region for the asterolds was certainly at a higher temperature than that for comets we do not expect the interstellar dust to be nearly as well preserved. Within the framework of the theory of Ruzmalkina and Maeva /39/ the temperature of the pre-solar nebula relevant to the asteroldal belt was 250-300 $\mathrm{K}$ which was sufflcient to evaporate all the dust volatiles whlle preserving a fraction of the organics. One factor which appears to provide a basis for believing the connection lies in the preservation $/ 36,40 /$ of the pre-solar isotopic abundances of the heavy noble gases $\mathrm{Ar}, \mathrm{Kr}$ and $\mathrm{Xe}_{\theta} \mathrm{in}$ the carbonaceous component. These elements are presumed to have been trapped in the interstellar organle refractory mantles and retained during asterold formation. Thus, although meteorites may be ldentified with the same interstellar dust ancestors as comets, they are like cousins rather then siblings.

Based on the observations of the largely amorphous, carbonaceous coatings in the Allende (C3V) meteorlte $/ 41,42,43 /$ Huss $/ 44 /$ has suggested that the matrices in the parent bodies of the $C 3 V, C 30$, and type 3 ordinary chondrites probably accreted from presolar dust that had lost the licy mantles. On the other hand he proposed that CI (C1) chondrites and the matrices of $\mathrm{C} 2$ chondrites probably accreted as bulk samples of presolar dust with some icy mantles intact - almost cometary. Parent body heating (not characteristic of comets) then caused the icy manties to react with the pine grained dust to produce the hydrothermal mineral assemblages now observed. The lcy mantles in comet dust evaporate rather than melt so that, although we should not be surprised by seeing some resemblance between CP IDP's and CI chondrites, the differences should also not be a surprise - there are no hydrated sillcates In low density IDP's. If IDP's are remants of comet dust they should more resemble the chemical and physical composition of the latter in which the $\mathrm{H}_{2} \mathrm{O}$ evaporated rather than melted. There is a monotonic sequence of carbonaceous content from interstellar dust to comet dust to IDP's to meteorites.

In Fig. 3 we summarlze the relationshlp between interstellar dust, interplanetary dust and meteors and meteorltes as concelved of here.

\section{CONCLUDING REMARKS}

We have to look to future space misslons to recover comet mater lal much more pristine than we can infer from flyby or even rendezvous mlssions. If the comet nucleus material can be retrieved from its depths and malntalned intact cryogenlcally for laboratory studies, we may hope to study not only its atomic and molecular compositions but also its morphology. Microprobes are being developed /45/ which w111 make investigations possible of submicron structures. If it should turn out that the intersteliar dust model is correct, individual grains whose mean lifetime before becoming part of a comet is about $5 \times 10^{9}$ yr will reveal cosmochemical evolution not only of the solar system but dating back a further 5 billion years before the earth's beginning - back to the earliest stages of the chemical evolution of the Milky Way. Dramatlc differences in isotoplc abundances could be expected on scales of microns. The next twenty to thirty years should be exciting ones indeed for studies of our origlns. 


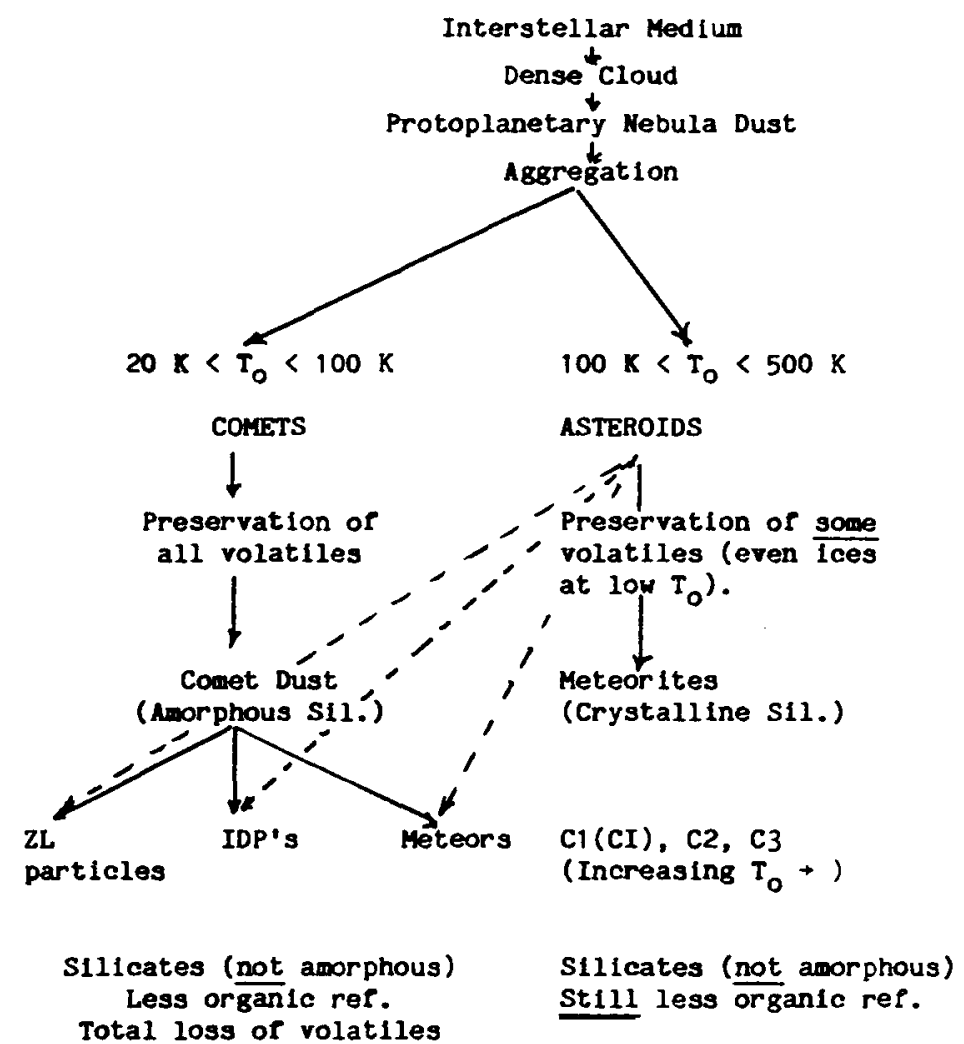

Fig. 3. Decrease of organles and increase of sillcate crystallinity according to aggregation temperature, $T_{0}$, and thermal history. 


\section{REFERENCES}

11/ Greenberg, J.M. and Chlewick1, G.C. "A Par-ultraviolet extinction law: what does it mean?", Astrophys. J., 272, 563-578 (1988).

12/ Greenberg, J.M., de Groot, M.S. and Van der Zwet, G.P. "Carbon components of interstellar dust", In: Polycyclic Aromatic Hydrocarbons and Astrophysics, ed. A. Leger, L.B. d'Hendecourt and N. Boccara (Reidel) 177-181 (1987).

13/ See "Polycyclic Aromatic Hydrocarbons and Astrophysics", ed. A. Leger, L.B. d'Hendecourt and N. Boccara (D. Reidel Pub.) (1987).

14/ Greenberg, J.M. "Dust in dense clouds. One stage in a cycle", Submillimetre Wave Astronomy, eds. Phillips, D. and Beckman, J.E., Cambridge University Press, 261-306 $(1982 a)$.

15/ Greenberg, J.M. "Dust in Diffuse Cloudg: One stage in a cycle", in: "Light on Dark Matter" ed. F P. Israel, (Reidel), 177-188 (1986).

16/ Schutte, W. Ph.D. Thesis University of Leiden "The evolution of interstellar organic grain mantles" $1-295(1988)$.

$17 /$ Greenberg, J.M. "The evidence that comets are made of Interstellar dust" in "Comet Halley 1986 - Worldwide Investigations, Results and Interpretations". Ellis Horwood Ltd., Chichester, England (eds. John Mason and Patrlch Moore), in press (1988).

18/ Chlewickl, G.C. and Greenberg, J.M., "Intersteliar circular polarization and the dielectric nature of dust grains", Astrophys. J., submitted (1988).

19/ Grim, R.J.A. and Greenberg, J.M. "Photoprocessing of $\mathrm{H}_{2} \mathrm{~S}$ in interstellar grain mantles as an explanation for $S_{2}$ in comets", Astr. Astrophys. 181, 155-168 (1987).

110/ Larson, H.P., Weaver, H.A., Mumma, M.J. and Drapatz, S. "Alrborne Infrared spectroscopy of comet wilson (19861) and comparisons with comet Halley", Astrophys. J. In press (1988).

111/ Greenberg, J.M. "What are comets made of? A model based on interstellar dust", in Comets, ed. Wilkening, L.L., University of Arizona Press, 131-163 (1982b).

112/ Greenberg, J.M. "Laboratory dust experiments - Tracing the composition of cometary dust", in: Cometary Exploration, ed. T.I.Gombos1 (Hungarian Academy of Sciences) 23-54 (1983).

113/ Greenberg, J.M. "Fluffy Comets", in: Asterolds, Comets and Meteors II, eds. C.-I. Lagerkvist, B.A. Lindblad, H. Lundstedt and H. Rickman, (Uppsala UnIversity Press) 221$223(1986)$.

114/ Krankowsky, D., Lämmerzah1, P., Herrwerth, I., Wower les, J., Eberhardt, P., Dolder, U., Herrmann, U., Schutte, W., Berthelier, J.J., Illlano, J.M., Hodges, R.R. and Hof fman, J.H., "In situ gas and Ion measurements at comet Halley", Nature, 321, 326-329 (1986).

115/ Festou, M.C., Feldman, P.D., A'Hearn, M.F., Arpigny, C., Cosmovicl, C.B., Danks, A.C. McFadden, L.A., Gilmozzi, R., Patriarchi, P., Tozz1, G.P., Wallis, M.K. and Weaver, H.A., "IUE observations of comet Halley during the Vega and Glotto encounters", Nature $321,361-363(1986)$.

$116 /$ Greenberg J.M., Grim, R.J.A. and Van IJzendoorn, L., "Interstellar $S_{2}$ in Comets", in: Comets, Asteroids, Meteorites II, eds. Lagerkvist, B., Lindblad, H., Lundstedt and H. Rlckman, Uppsala press, 218-220 (1985).

117 / Whlttet, D.C.B., Longmore, A.J., McFadzean, A.D., 1985, "Solid CO in the Taurus dark clouds", Mon. Not. R. Astron. Soc. 216, 45P-50P.

118/ Greenberg, J.M. 1983, "Interstellar dust, comets, comet dust and carbonaceous meteorites", In: Asterolds, Comets Meteors, eds. C.I. Lagerkvist and H. Rickman, Uppsala Unlversity Press, 259-268.

19/ Eberhardt, P., Krankowsky, D., Schulte, W., Dolder, U., Lämmerzahl, Ph., Bertheller, J.J., Woweries, J., Stubbeman, U., Hodges, R.R., Hof fman, J.H., and Illiano, J.M. Astron. Astrophys. 187, 481-484 (1987).

$120 /$ Balsiger, H., Altwegg, K., Buhler, F., Geiss, J., Chielmettl, A.C., Goldstein, B.E., Goldstein R., Huntress, W.T., Ip, W.-H., Lazarus, A.J., Meier, A., Neugebauer, M., Rettenmund, U., Rosenbauer, H., Schwenn, R., Sharp, R.D., Shelley, E.G., Ungstrup, E. and Young, D.T. "Ion composition and dynamies at comet Halley", Nature, 321, 330-334 (1986).

121/ Van de Bult, C.E.P.M., Greenberg, J.M., Whittet, D.C.B., "Ice in the Taurus molecular cloud: modelling of the $3 \mu \mathrm{m}$ profile, Mon. Not. R. Astron. Soc., 214, 289-305 (1984). 
122/ d'Hendecourt, L.B., Allamandola, L.J. and Greenberg, J.M. "Time dependent cheistry in dense molecular clouds I. Grain surface reactions, gas/grain interactions and lnfrared spectroscopy", Astron. Astrophys., 152, 130-150 (1985).

123/ Delsemme, A.H., "Chemical composition of cometary nuclei", in: Comets, ed. L.L. Wilkening, University of Arizona Press, 85-130 (1982).

$124 / \mathrm{Kissel} \mathrm{J}$, and Krueger, F.R. "The organic components in dust from Halley as measured by the PUMA mass spectrometer on board Vega $1 "$, Nature 326, 755-760 (1987).

125/ Kissel, J., Brownlee, D.E., Büchler, K.; Clark, B.C., Fechtig, H., Grün, E., Hornung, K., Igenbergs, E.B., Jessberger, E.K., Krueger, F.R., Kuczera, H., McDonnell, J.A.M., Morfili, G.M., Rahe, J., Schwehm, G.H., Sekanina, Z., Utterback, N.G., Volk, H.J. and Zook, H.A., "Composition of comet Halley dust particles from Glotto observations", 1986, Nature, 321, 336-337 (1986a).

/26/ Kissel, J., Sagdeev, R.Z., Bertaux, J.L., Angarov, V.N., Audouze, J., Blamont, J.E., Buchler, K., Evlanov, E.N., Fechtig, H., Fomenkova, M.N., von Hoerner, H., Inogamov, N.A., Khromov, V.N.. Knabe, W., Krueger, F.R., Langevin, Y. Leonas, V.B., LevasseurRegourd, A.C., Managadze, G.G., Podkolzin, S.N., Shaplro, V.D., Tabladyev, S.R. and Zubkov, B.V., "Composition of comet Halley dust particles from Vega observations", Nature, 321, 280-282 (1986b).

127/ Greenber $\frac{3}{8}$, J.M., Zhao, N-S., and Hage, J., Advances in Space Research (This Volume) "The intersteliar dust model of comet dust constrained by $3.4 \mu \mathrm{m}$ and 10 um emissions" (1989).

128/ McDonnell, J.A.M. et al, "The dust distribution within the inner coma of comet p/Haliey 19821: encounter by Glotto's impact detection", Astron. Astrophys. 187, 719-741 (1987).

$129 /$ Hong, S.S. and Kwon, S.M., "Spatlally Varying Optical Properties of the Zodiacal Dust" In: IAU Joint Discussion IV: The Cosmic Dust Connection (1988).

$130 /$ Fechtig, H., "The Interplanetary dust environment beyond IAU and in the vicinity of the ringed planets", Adv. Sp. Res. Vol. 4 no. 9, 5-11 (1984).

$131 /$ Whipple, F. "On maintaining the meteorite complex" in the zodiacal Light and the Interplanetary Medium, ed. J.L. Welnberg NASA-SP 150, 409-426 (1976).

$132 / 01 s s o n-S t e e l, D$. "The origin and physical characteristics of meteoroids", this volume (1988).

133/ Dohnanyi, J.S., "Sources of Interplanetary dust: asteroids" in Lecture Notes in Physlcs (eds. H. Elsăsser and H. Fecht1g, Berlin: Springer-Verlag) 48, $29(1976)$.

134/ Humes, D.H., Alvarez, J.M., O'Neal, R.L. and KInard, W.H. "The interplanetary and near Jupiter meteorold environments", J. Geophys. Res. 79, 3677 (1974).

135/ Muka1, T. and Fechtig, H. "Packing effect of fluffy particles. Planet Space Sci. 31 , 655 $(1983)$.

136/ Brownlee, D.E. "The composition of dust particles tn the environment of Comet halley", in "Comet Halley 1986 - Worldwide Investigations, Results and Interpretations", Elis Horwood, Ltd. Chichester England (eds. John Mason and Patrick Moore) in press (1988).

$137 /$ Wopenka, B. Earth and Planet Sc1. Lett. 88,221 (1988).

138 / Vernian1, F., "Physical parameters of faint meteors", J. Geophys. Res. 78, 8429-8462 (1973).

139/ Rlumaikina, T.V. and Maeva, S.V. "Process of formation of the protoplanetary disk", in COSPAR XXVII Heisinki proceedings (1988).

$140 /$ Huss, G.R. and Alexander, C.Jr. "On the presolar or igin of the "Normal Planetary" noble gas component in meteorites", J. Geophys. Res. 92, no. 134, E710-E716 (1987).

141 Green, H.W. III, Radeliffe, S.V., and Hever, A.H. "Allende meteorite: a high voltage electron petrographic study", Sclence 172, 936-939 (1971).

142/ Bunch, T.E. and Chang, S. "Carbonaceous chondrite phylosilicates and light element geochemistry as indicators of parent body processes and surface conditions, Geochim. Cosmoch im. Acta 44, 1543-1577 (1980).

143/ Bauman, A.J., Devany, J.R. and Bollin, E.M. "Allende meteorlte carbonaceous phase: intractable nature and scanning electron morphology, Nature, 241, 264-267 (1973).

144/ Huss, G.R. "The role of presolar dust in the formation of the solar system", Icarus (1987).

/45/ Bradley, J.R. and Browniee, D.E. "Cometary particles: Thin sectioning and electron beam analysis", Science, 231, 1542-1544 (1986). 